\title{
Quit outcomes among clients ineligible for cessation medication through the state quitline: a retrospective, observational study
}

Adrienne B. Lent ${ }^{*}$, Patrick A. O'Connor ${ }^{2}$, Ryan C. Reikowsky' ${ }^{1}$ Uma S. Nair ${ }^{1}$ and Melanie L. Bell ${ }^{3}$

\begin{abstract}
Background: Distribution of tobacco cessation medications through state quitlines increases service utilization and quit outcomes. However, some state quitlines have moved to models in which callers are instructed to obtain quit medications through their health insurance pharmaceutical benefit. We aimed to investigate the impact of this policy on medication access and quit outcomes in the state quitline setting for clients who must obtain covered medications through the state Medicaid program. We hypothesized that clients with Medicaid who were referred by their healthcare provider would be more likely to report using quit medication and have higher quit rates compared to clients with Medicaid who engaged the quitline on their own.
\end{abstract}

Methods: An observational, retrospective study was conducted using state quitline clients with Medicaid health insurance who were ineligible for quitline provided cessation medications. Clients were stratified by referral type: self-referred, passively referred, and proactively referred. Unadjusted and adjusted logistic regression was used to estimate the effect of referral type on both quit status and cessation medication use.

Results: Proactively referred clients were less likely to use quit medication (53.6\%) compared to self (56.9\%) and passively referred clients (61.1\%). Proactively referred clients had lower quit rates (31.4\%), as compared to passively referred (36.0\%) and self-referred (35.1\%). In adjusted models, proactively referred clients were significantly less likely to be quit than passively referred clients $(\mathrm{OR}=0.75,95 \% \mathrm{Cl}: 0.56,0.99)$. There were no statistically significant differences in medication use or number of coaching sessions among proactive, passive, and self-referred clients in adjusted models.

Conclusions: In adjusted models, medication use did not significantly differ by mode of entry in this population of Medicaid beneficiaries. Psychosocial factors such as intention to quit in the next 30 days, social support for quitting, education level, race, and ethnicity impacted quit status and differed by mode of entry. Quitlines should use tailored strategies to increase engagement and reduce barriers among proactively referred clients.

Keywords: Smoking, Tobacco, Quitline, Medicaid, Telephone counseling, Cessation medication

\footnotetext{
* Correspondence: adriennelent@email.arizona.edu

'Health Promotion Sciences, University of Arizona, Mel and Enid Zuckerman

College of Public Health, 1295 N Martin Ave, Tucson, AZ 85724, USA

Full list of author information is available at the end of the article
}

(c) The Author(s). 2018 Open Access This article is distributed under the terms of the Creative Commons Attribution 4.0 International License (http://creativecommons.org/licenses/by/4.0/), which permits unrestricted use, distribution, and reproduction in any medium, provided you give appropriate credit to the original author(s) and the source, provide a link to the Creative Commons license, and indicate if changes were made. The Creative Commons Public Domain Dedication waiver (http://creativecommons.org/publicdomain/zero/1.0/) applies to the data made available in this article, unless otherwise stated. 


\section{Background}

Smoking is the leading preventable cause of premature death and disease in the United States [1]. Smoking rates have decreased significantly since the release of the first Surgeon General's Report on Smoking and Health in 1964 but remain disproportionately high among low income individuals $[2,3]$. Tobacco use rates for Medicaid beneficiaries are nearly double the privately insured population and $11 \%$ of Medicaid expenditures ( $\$ 22$ billion) nationally are attributable to smoking-related diseases $[4,5]$.

Tobacco cessation medications, including over-the-counter nicotine replacement therapy (NRT), are effective in helping people quit. Using NRT, even without behavioral counseling, can increase the likelihood of cessation by $50-70 \%$ [6]. In the state quitline setting, distribution of nicotine replacement therapy at no cost to clients results in higher client quit rates when compared to clients who do not receive quitline-provided medication $[7,8]$. Therefore, access to cessation medications plays an important part in quitting smoking.

Quitlines are an effective, accessible, and evidence-based public health approach to delivering quit medication support as well as behavioral counseling $[9,10]$. Access to NRT, while facilitated in the quitline setting, has been somewhat impeded with reductions in state quitline funding. Some state quitlines (such as North Carolina and Alabama) have begun to restrict services to individuals who can receive NRT through their insurance plan, while continuing to provide services to high-risk populations (e.g., uninsured) who do not have access to covered quit medication treatments outside the state quitline setting [11]. Most health insurers are required to cover tobacco cessation treatment as a preventive service under the Affordable Care Act, which includes all seven Food and Drug Administration (FDA) approved quit medications without copays or prior authorization [12]. Therefore, some state quitlines have moved to models in which callers are instructed to obtain quit medications through their health insurance pharmaceutical benefit. While navigating callers to an external health system for quit medications may decrease quitline costs, the impact of this policy on quit medication access and quit outcomes, especially among the high-risk Medicaid population, in the state quitline setting is unknown. While previous studies have examined quit rates and medication utilization among clients when NRT is distributed through the state quitline [7, 8, 13, 14], little is known about quit medication access and the impact on cessation rates among quitline clients who are instructed to obtain health plan covered quit medications external to the state quitline.

Further, while most health insurers cover quit medications, they are often underutilized. The structure of obtaining insurance-covered cessation medications may pose a barrier to access since members must get a prescription from their healthcare provider and fill it at an in-network pharmacy. An in-network pharmacy is a pharmacy that is contracted with a health plan to provide pharmacy services to that health plan's members. While obtaining a prescription may be easy for those with private insurance, it may be more difficult for low-income individuals with Medicaid who may experience delays in care in an often understaffed healthcare system $[15,16]$. Additionally, a lack of awareness of health insurance cessation medication benefits may contribute to low utilization of covered quit medications; however, evidence suggests that advice from a healthcare provider to quit is an important predictor of cessation medication use, especially among Medicaid members [17].

Medicaid beneficiaries in Arizona who enroll in state quitline services are ineligible for quitline provided NRT. Instead, these clients are instructed to obtain a prescription through a healthcare provider to secure quit medications covered by their health plan. Using a sample of Medicaid quitline clients in Arizona, this paper examined whether cessation medication use and quit rates vary between clients who were referred or advised to enroll in services by their healthcare provider compared to those self-initiating contact with the quitline. Data for this study were obtained from Medicaid beneficiaries enrolled in the Arizona Smokers' Helpline (ASHLine). This study was limited to Medicaid beneficiaries in Arizona since data were obtained from Arizona's state quitline. Clients ineligible for quitline provided NRT who want medication are required to obtain insurance covered quit medications with a prescription that must be filled at a pharmacy. Therefore, we hypothesized that clients with a direct connection to a healthcare provider would be more likely to use quit medications and subsequently have higher quit rates than those who engaged the quitline on their own. We hypothesized that the mechanism for increased access to cessation medication among clients is connection to a healthcare provider. Furthermore, there is research that shows that medication use and quit rates differ by all three quitline modes of entry [18]. Our primary objective was to examine differences in cessation medication use and our secondary objective was to examine differences in quit rates. Our exploratory objective was to test whether cessation medication use mediated the effect of referral type on quit status, if there was evidence that referral type was associated with cessation medication use and quit rates.

\section{Methods}

\section{Study design, setting and participants}

The Arizona Smokers' Helpline (ASHLine), Arizona's state-funded tobacco quitline, provides free phone-based behavioral counseling to all Arizona residents. ASHLine provides no-cost NRT to clients not covered by Arizona's 
state Medicaid program (i.e., uninsured and privately insured). ASHLine does not provide free NRT to those who are covered by Arizona's Medicaid insurance since this state program covers twelve weeks of the seven FDA-approved cessation medications twice a year. ASHLine educates and assists clients with Medicaid with navigating the process of obtaining insurance-covered medications, which includes getting a prescription from their primary care provider and filling it at an in-network pharmacy.

A retrospective analysis was performed using ASHLine data for clients who reported having Medicaid health insurance and who were enrolled in tobacco cessation services between January 2011 and June 2016. Descriptive data were collected during the client intake survey at the time of enrollment into the program. A trained, external evaluation team collected self-reported medication use and quit status through a telephone survey at seven months after program enrollment as a part of standard quitline evaluation practices recommended by the North American Quitline Consortium (NAQC) [19]. During the study period, 49,284 individuals enrolled in ASHLine and 11,192 (22.8\%) had Medicaid. Those who were missing mode of entry $(n=267)$ and medication use or quit status $(n=7528)$ data were excluded. The final sample size used for crude analyses was $3397=30 \%$ of the original sample; for adjusted analysis the sample size was
2289 clients (20\% of the original sample). Figure 1 shows the criteria used to select the clients included in the crude and adjusted analyses.

\section{Measures}

Our primary outcomes of interest were (a) medication use, which was defined as self-reporting using any of the seven FDA-approved cessation medications (nicotine gum, nicotine patch, nicotine lozenge, nicotine inhaler, nicotine nasal spray, Varenicline (Chantix), and Bupropion (Zyban)) during a client's quit attempt, and (b) quit status at seven months post program enrollment, defined as self-reporting not having used tobacco within the last 30 days. The independent variable was referral type (proactive, passive, and self). Proactively referred clients were contacted by the quitline after receipt of an electronic or fax referral from their healthcare provider. Passively referred clients self-initiated contact with the quitline on their own after receiving advice from a healthcare provider. Self-referred clients also self-initated a call to the quitline but did so after seeing an advertisement or hearing about the program from a friend or family member. Self and passive referral status were identified at enrollment by asking clients how they heard about ASHLine. Controlling variables gathered at program enrollment included clients' self-reported: age; gender (female, male); education (high school or less, some college or more); race

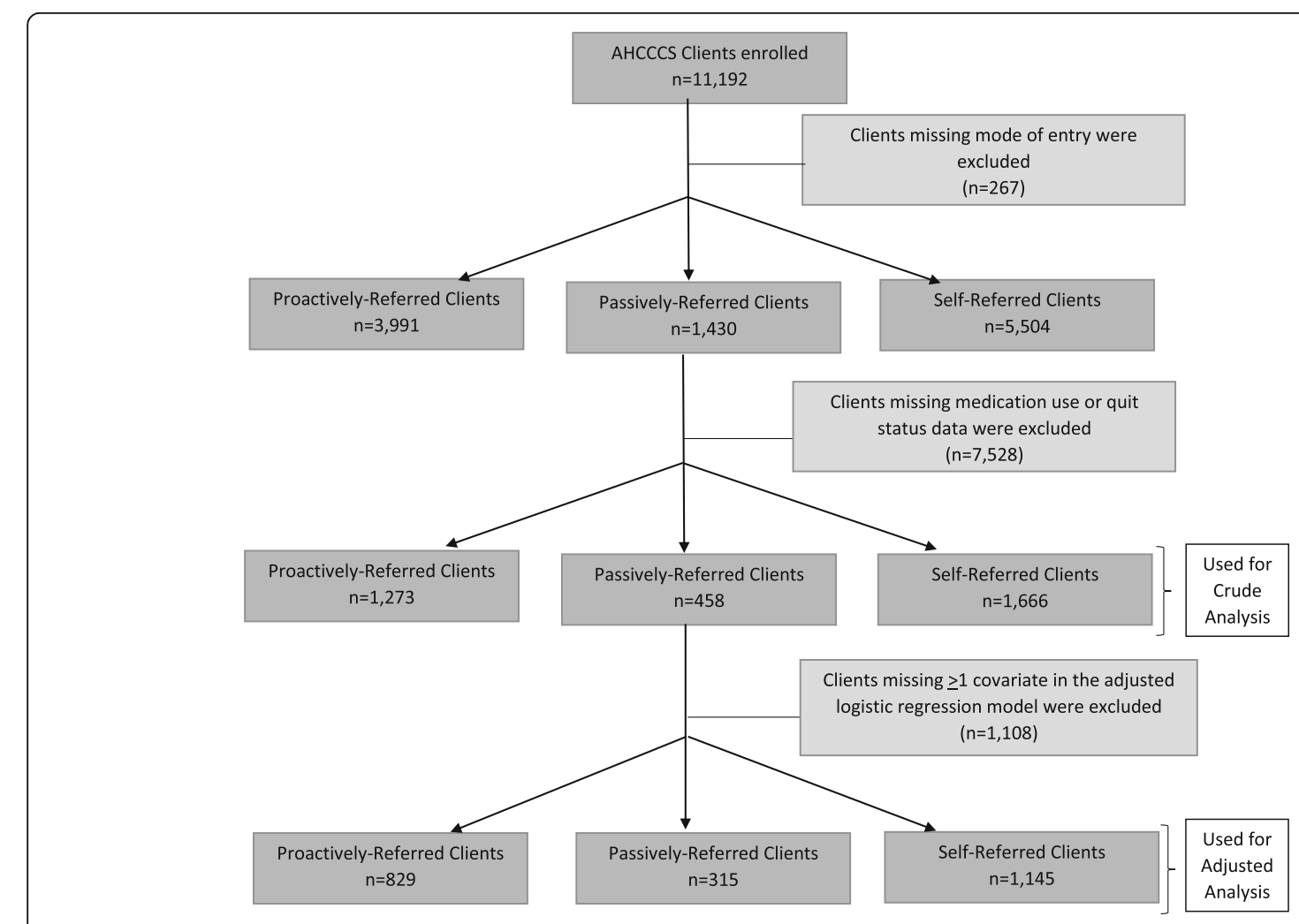

Fig. 1 Flow Diagram 
(White, Black, Asian, American Indian, multi-racial, other); diagnosis of a chronic condition including asthma, cancer, chronic obstructive pulmonary disorder, diabetes, heart disease, and hypertension (yes, no); mental health condition including depression, bipolar, schizophrenia, anxiety, and alcohol or drug abuse (yes, no); intensity of physical addiction to nicotine as measured by the commonly used valid and reliable Fagerstrom Test for Nicotine Dependence (measured on a $0-10$ scale with higher scores indicating greater dependence) [20-23]; social support to quit smoking measured by a five-point Likert scale; presence of other smokers in the home (yes, no); and confidence to quit smoking for at least $24 \mathrm{~h}$ (dichotomized as not confident or somewhat confident versus confident, very confident, or extremely confident). Number of completed coaching sessions was assessed after program completion.

\section{Statistical methods}

ANOVA and chi-square tests were used to evaluate differences in baseline and seven month follow-up factors stratified by referral type (proactive, passive, and self). Unadjusted and adjusted logistic regression was used to estimate the effect of referral type on both quit status and cessation medication use at seven month follow-up. Adjusted models included the variables listed above, were pre-specified; based on background knowledge; literature review that show they are associated with smoking behavior; and our own extensive experience with these data [18, 24-27]. These variables are collected by ASHLine as a part of their intake process and are based on the minimal data set for state quitlines as outlined by NAQC [28]. Odds ratios (OR) and 95\% confidence intervals $(\mathrm{CI})$ were estimated. The fit of each model was evaluated using the Hosmer-Lemeshow test [29]. The assumption of linearity in the logit was assessed for continuous variables using restricted cubic splines [30]. Baseline characteristics of clients with seven month follow-up were compared with those without follow-up.

\section{Exploratory analysis}

We also planned to test whether cessation medication use mediated the effect of referral type on quit status, if it was found that referral type was associated with cessation medication and quit rates. Mediation analysis aims to quantify the relative direct and relative indirect effects of an exposure (referral type) on an outcome (quit status) through an intermediary variable (cessation medication use), known as the mediator. The relative direct effect is the effect the exposure has on the outcome while controlling for the mediator. All analyses were performed using SAS version 9.4 (SAS Institute, Cary, North Carolina).

\section{Results}

Client characteristics by mode of entry

Compared to self and passively referred clients, proactively referred clients were more likely to be male, non-white (Black, Asian, American Indian, multi-racial, other), Hispanic, have a high school education or less, and report having other smokers in the home. Compared to proactively referred clients, self and passively referred clients were more likely to smoke more cigarettes per day, have higher nicotine dependence levels, have more social support, and intend to quit in the next thirty days. Passively referred smokers were more likely to have a chronic condition compared to self and proactively referred clients (Table 1 ). Proactively referred clients were less likely to use quit medication (53.6\%) compared to self $(56.9 \%)$ and passively referred clients (61.1\%). Proactively referred clients had lower quit rates (31.4\%), as compared to passively referred (36.0\%) and self-referred (35.1\%).

\section{Adjusted odds of quit status and medication use}

Unadjusted and adjusted results were similar (Table 2), although odds ratios comparing referral types were changed slightly, with marginally significant comparisons becoming non-significant and vice versa. We report the adjusted results here. Proactively referred clients were significantly less likely to be quit than passively referred clients $(\mathrm{OR}=0.75,95 \% \mathrm{CI}$ : 0.56 , 0.99). There was no evidence of difference in quit status between self-referred and passively referred clients $(\mathrm{OR}=1.12,95 \% \mathrm{CI}: 0.85,1.47)$ or between self-referred and proactively referred clients $(\mathrm{OR}=$ $0.84,95 \%$ CI: $0.68,1.02)$. Variables that negatively affected quit status included self-reported mental health condition ( $\mathrm{OR}=0.70,95 \% \mathrm{CI}: 0.58,0.85)$ and nicotine dependence score $(\mathrm{OR}=0.92,95 \% \mathrm{CI}: 0.88,0.95)$. Number of coaching sessions $(\mathrm{OR}=2.87,95 \% \mathrm{CI}$ : $2.38,3.45)$ and a client's intention to quit tobacco in the next 30 days $(\mathrm{OR}=2.29,95 \% \mathrm{CI}: 1.41,3.71)$ significantly increased the odds of being quit.

In the adjusted model (unlike the unadjusted model), medication use did not differ significantly among the three groups, with $\mathrm{OR}=1.1$ for passively versus self-referred clients (95\% CI: $0.85,1.43$ ); OR $=0.91$ for proactively versus self-referred clients (95\% CI: 0.75 , $1.09)$; and $\mathrm{OR}=0.82(95 \% \mathrm{CI}, 0.63,1.08)$ for proactive versus passively referred clients. Higher education (OR $=1.37,95 \% \mathrm{CI}: 1.16,1.63)$, a higher nicotine dependence score $(\mathrm{OR}=1.04,95 \% \mathrm{CI}: 1.00,1.08)$, and receiving 5 or more coaching sessions $(\mathrm{OR}=1.32,95 \% \mathrm{CI}: 1.11,1.57)$ were significantly associated with a client using medication. A 10-year increase in age increased the odds of using medication during the quit attempt $(\mathrm{OR}=1.08$, 95\% CI: 1.01, 1.16). 
Table 1 Descriptive statistics ( $N=3397)$. Mean (SD) shown for continuous variables, frequencies (\%) shown for categorical variables

\begin{tabular}{|c|c|c|c|c|}
\hline \multirow[t]{2}{*}{ Characteristics } & \multicolumn{3}{|l|}{ Referral type } & \multirow[t]{2}{*}{$P$-value } \\
\hline & Self $(n=1666)$ & Passive $(n=458)$ & Proactive $(n=1273)$ & \\
\hline Age (years) & $48.7(13.0)$ & $50.1(11.6)$ & $49.1(12.9)$ & 0.11 \\
\hline Gender & & & & 0.02 \\
\hline Male & $572(34.4)$ & $158(34.7)$ & $494(39.1)$ & \\
\hline Female & 1089 (65.6) & $298(65.4)$ & $768(60.9)$ & \\
\hline Race & & & & $0.01 *$ \\
\hline White & $1211(81.6)$ & $327(79.6)$ & $782(76.9)$ & \\
\hline Black or AA & $144(9.7)$ & $44(10.7)$ & $138(13.6)$ & \\
\hline Asian & $6(0.4)$ & $3(0.7)$ & $11(1.1)$ & \\
\hline American Indian & $40(2.7)$ & $7(1.7)$ & $38(3.7)$ & \\
\hline Multiracial & $45(3.0)$ & $17(4.1)$ & $18(1.8)$ & \\
\hline Other & $38(2.6)$ & $13(3.2)$ & $30(3.0)$ & \\
\hline Education & & & & $<0.0001$ \\
\hline High school or less & $834(50.1)$ & $241(52.6)$ & $782(61.4)$ & \\
\hline Some college or more & $832(49.9)$ & $217(47.4)$ & $491(38.6)$ & \\
\hline Hispanic & $251(18.2)$ & $66(17.3)$ & $309(31.8)$ & $<0.0001$ \\
\hline Children living in the household & $435(31.1)$ & $107(28.1)$ & $334(33.2)$ & 0.17 \\
\hline Family size & $2.4(1.7)$ & $2.5(1.8)$ & $2.6(1.8)$ & 0.03 \\
\hline Chronic condition & $1066(66.7)$ & $327(74.5)$ & $886(72.1)$ & 0.01 \\
\hline Mental health condition & $951(59.9)$ & $273(63.5)$ & $725(59.5)$ & 0.33 \\
\hline \multicolumn{5}{|l|}{ Baseline tobacco use behaviors } \\
\hline Other smokers in the home & $626(46.8)$ & $176(47.6)$ & $523(52.5)$ & 0.02 \\
\hline Smoking allowed in the home & & & & 0.05 \\
\hline Not allowed & $731(52.3)$ & $202(52.2)$ & $482(47.7)$ & \\
\hline Allowed in some places & $221(15.8)$ & $67(17.3)$ & $201(20.2)$ & \\
\hline Allowed anywhere & $446(31.9)$ & $118(30.5)$ & $325(32.2)$ & \\
\hline Number of cigarettes smoked per day, mean (SD) & $16.6(10.1)$ & $17.6(11.7)$ & $14.7(8.9)$ & $<0.0001$ \\
\hline Nicotine dependence, mean (SD) & $5.0(2.3)$ & $5.1(2.3)$ & $4.6(2.2)$ & 0.01 \\
\hline \multicolumn{5}{|l|}{ Other baseline factors } \\
\hline Number of quit attempts during past 12 months, mean (SD) & $2.8(7.8)$ & $2.8(7.5)$ & $2.0(3.4)$ & 0.01 \\
\hline Confidence to quit (for at least 24 h) & & & & 0.56 \\
\hline Poor, fair & $237(16.8)$ & $68(17.4)$ & $186(18.5)$ & \\
\hline good, very good, excellent & $1170(83.2)$ & $323(82.6)$ & $818(81.5)$ & \\
\hline Intention to quit (in the next 30 days) & & & & $<0.0001$ \\
\hline No, I don't know & $41(3.6)$ & $11(2.8)$ & $80(7.8)$ & \\
\hline Yes, I have already quit & $1369(96.4)$ & $388(97.2)$ & $945(92.2)$ & \\
\hline Social support & & & & 0.01 \\
\hline Poor, fair & $357(25.3)$ & $75(19.3)$ & $272(27.4)$ & \\
\hline good, very good, excellent & $1055(74.7)$ & $313(80.7)$ & $720(72.6)$ & \\
\hline \multicolumn{5}{|l|}{ Post-baseline factors } \\
\hline Reach rate ${ }^{* *}$ & $58.0 \%$ & $56.4 \%$ & $58.5 \%$ & 0.42 \\
\hline Number of coaching sessions before 7-month follow-up & & & & 0.92 \\
\hline $0-4$ & $994(59.7)$ & $278(60.7)$ & $764(60.0)$ & \\
\hline $5+$ & $672(40.3)$ & $180(39.3)$ & $509(40.0)$ & \\
\hline
\end{tabular}


Table 1 Descriptive statistics ( $N=3397)$. Mean (SD) shown for continuous variables, frequencies (\%) shown for categorical variables (Continued)

\begin{tabular}{|c|c|c|c|c|}
\hline \multirow[t]{2}{*}{ Characteristics } & \multicolumn{3}{|l|}{ Referral type } & \multirow[t]{2}{*}{$P$-value } \\
\hline & Self $(n=1666)$ & Passive $(n=458)$ & Proactive $(n=1273)$ & \\
\hline Days in program & $85.1(83.5)$ & $80.7(76.8)$ & $79.1(67.5)$ & 0.11 \\
\hline Others smokers at home (7-month follow-up) & $506(30.8)$ & $156(34.5)$ & $418(33.4)$ & 0.19 \\
\hline Medication use & $948(56.9)$ & $280(61.1)$ & $682(53.6)$ & 0.01 \\
\hline Quit & 585 (35.1) & 165 (36.0) & 400 (31.4) & 0.06 \\
\hline
\end{tabular}

Boldface indicates statistical significance $(p<0.05)$

* Fisher's Exact Test used for comparisons

${ }^{* *}$ Reach rate is calculated using data for all clients with a mode of entry $(n=10,925)$

\section{Missing data and dropout}

Baseline comparisons of clients included in the adjusted analysis with clients with missing data (either follow-up or one of the covariates from the adjusted models) are shown in Additional file 1: Table S1. We report statistically significant comparisons, but advise that the large sample size can make very small differences statistically significant. Compared to clients in the final adjusted models, those who dropped out or had incomplete data were slightly younger, slightly more likely to be male, slightly more likely to have children living in their household, slightly more likely to have a chronic condition, slightly more likely to have other smokers in the home, slightly more likely to have a higher frequency of tobacco use, have slightly more quit attempts in the past 12 months, and have slightly less social support.

\section{Mediation}

Mediation results are not given, as the evidence for association between referral type and medication and cessation rates was not strong.

\section{Discussion}

\section{Key findings}

The purpose of this study was to examine differences in medication utilization and quit outcomes by mode of entry in a high-risk, low-income group of clients who are ineligible for quitline provided NRT (i.e., ASHLine clients with Medicaid insurance). The hypothesis that ASHLine Medicaid clients who were referred by a healthcare provider (proactive and passive) would have higher medication use rates and subsequently higher quit rates compared to clients who were self-referred was not strongly supported. Although there were significant differences in medication use across proactive, passive, and self-referred clients in unadjusted models, upon adjusting, these differences were no longer significant. However, medication use overall in this sample was low (57\%). This lack of variation in medication use across the three groups may be explained by overall low utilization of medication in this population, perhaps due to the increased barriers in obtaining a prescription from a health care provider (vs. the quitline providing/mailing out the medication). Proactively referred clients were less likely to quit compared to passively referred clients in adjusted models. The marginal unadjusted odds ratio in quit status between passively and self-referred clients decreased from 0.85 to 0.84 , but became statistically non-significant in adjusted models. The client characteristics of proactively referred clients differed from those who engaged the quitline on their own and may play a more critical role in cessation compared to medication use. Proactively referred clients had a lower intention to quit in the next 30 days, social support for quitting, education level, and were more likely to be non-white, Hispanic. Therefore, proactively referred clients with Medicaid represent a high-risk group of tobacco users with unique barriers to quitting.

\section{Interpretation of results}

Our analysis showed that factors other than medication use impacted the odds of quitting. Proactively referred clients with Medicaid differed from their passive and self-referred peers, which may explain the differences in quit outcomes. Proactively referred clients were twice as likely to report having no intention to quit in the next 30 days compared to passive and self-referred clients who initiate their own engagement with the quitline. Although intention to quit may help explain the difference in quit outcomes among passive and proactive referrals, it does not explain why the quit rates between proactive and self-referred clients were not found to be different after adjustment. It may be possible that passively referred clients are unique - they receive advice from a health care provider to quit tobacco (a known factor in influencing smoking behavior change [17]) and they self-initiate a call to the quitline (an indication of a high motivation to quit). This synergistic effect of health care provider messaging combined with a high motivation to quit may explain the differences in quit outcomes between passive and proactive clients. Additionally, quit rates between proactive and self referrals may not have differed in adjusted models because each group is only 
Table 2 Odds ratios, 95\% confidence intervals, and p-values for the outcomes of quit status and medication use

\begin{tabular}{|c|c|c|c|c|}
\hline & Quit Status & & Medication use & \\
\hline Unadjusted Model & OR $(95 \% \mathrm{Cl})$ & $p$-value & OR $(95 \% \mathrm{Cl})$ & $p$-value \\
\hline \multicolumn{5}{|l|}{ Referral type } \\
\hline Self-referral & Ref & & Ref & \\
\hline Passive referral & $1.04(0.84,1.29)$ & 0.72 & $1.19(0.96,1.47)$ & 0.10 \\
\hline Proactive referral & $0.85(0.73,0.99)$ & 0.04 & $0.87(0.76,1.01)$ & 0.07 \\
\hline Proactive vs Passive & $0.81(0.65,1.02)$ & 0.07 & $0.73(0.59,0.91)$ & 0.01 \\
\hline \multicolumn{5}{|l|}{ Adjusted Model } \\
\hline \multicolumn{5}{|l|}{ Referral type } \\
\hline Self-referral & Ref & & Ref & \\
\hline Passive referral & $1.12(0.85,1.47)$ & 0.42 & $1.10(0.85,1.43)$ & 0.46 \\
\hline Proactive referral & $0.84(0.68,1.02)$ & 0.08 & $0.91(0.75,1.09)$ & 0.29 \\
\hline Proactive vs Passive & $0.75(0.56,0.99)$ & 0.05 & $0.82(0.63,1.08)$ & 0.15 \\
\hline Age (per 10 years) & $0.93(0.86,1.01)$ & 0.07 & $1.08(1.01,1.16)$ & 0.02 \\
\hline \multicolumn{5}{|l|}{ Gender } \\
\hline Female & Ref & & Ref & \\
\hline Male & $1.05(0.87,1.28)$ & 0.59 & $0.90(0.75,1.07)$ & 0.23 \\
\hline \multicolumn{5}{|l|}{ Education } \\
\hline High school or less & Ref & & Ref & \\
\hline Some college or more & $1.14(0.95,1.37)$ & 0.17 & $1.37(1.16,1.63)$ & 0.01 \\
\hline \multicolumn{5}{|l|}{ Chronic condition } \\
\hline No & Ref & & Ref & \\
\hline Yes & $1.00(0.81,1.22)$ & 0.96 & $1.21(1.00,1.46)$ & 0.05 \\
\hline \multicolumn{5}{|l|}{ Mental health condition } \\
\hline No & Ref & & Ref & \\
\hline Yes & $0.70(0.58,0.85)$ & 0.01 & $0.96(0.81,1.15)$ & 0.69 \\
\hline Fagerstrom test for nicotine dependence & $0.92(0.88,0.95)$ & $<.0001$ & $1.04(1.00,1.08)$ & 0.04 \\
\hline \multicolumn{5}{|c|}{ Number of coaching sessions before 7 month follow-up } \\
\hline $0-4$ & Ref & & Ref & \\
\hline $5+$ & $2.87(2.38,3.45)$ & $<.0001$ & $1.32(1.11,1.57)$ & 0.01 \\
\hline \multicolumn{5}{|l|}{ Social support } \\
\hline Good, very good, excellent & Ref & & Ref & \\
\hline Poor, fair & $0.98(0.80,1.21)$ & 0.87 & $1.10(0.91,1.34)$ & 0.32 \\
\hline \multicolumn{5}{|l|}{ Other smokers in the home } \\
\hline No & Ref & & Ref & \\
\hline Yes & $0.98(0.81,1.17)$ & 0.79 & $0.96(0.81,1.14)$ & 0.62 \\
\hline Intention to quit (in the next 30 days) & Ref & & Ref & \\
\hline No, I don't know & $2.29(1.41,3.71)$ & 0.01 & $1.37(0.94,1.98)$ & 0.10 \\
\hline Yes, I have already quit & & & & \\
\hline
\end{tabular}

Values in bold are statistically significant at the 0.05 level

getting one effect: advice from a healthcare provider or a high motivation to quit. Additional factors that may contribute to the observed differences in tobacco cessation status are the baseline barriers to quitting associated with clients who are proactively referred. Our analysis of client characteristics by mode of entry suggests that proactively referred clients are more likely to be Hispanic, non-white individuals with social and environmental barriers to quitting (e.g., lack of social support, living with other smokers, and low education levels), which could negatively impact their likelihood of success. 


\section{Relation to other literature}

The findings from this study are consistent with other research that has shown proactively referred clients may be fundamentally different than clients who initiate their own engagement with the state. A study conducted by the Massachusetts state quitline, which offered free NRT to all callers, found that provider referred clients were more likely to be less educated, non-white (Black or other), not as ready to quit and have lower quit rates compared to self-referred clients [31]. Another study conducted by the Ohio state quitline found similar results indicating that clients proactively referred by a healthcare provider were less motivated to quit and educated compared to self-referred clients [32]. A recent study also found that proactively referred clients had different characteristics than from those who engaged the quitline on their own and were more likely to be non-white (Black or other), less educated, have less social support, and have other smokers in the home [18]. Therefore, proactively referred clients with Medicaid are a high-risk group who faces additional barriers to quitting. These client characteristics may be an important determination of cessation regardless of quitline provided NRT.

Quitlines could benefit from tailoring services and creating policies that are better suited to meet the unique needs of the proactively referred population. Quitline staff should use tailored strategies, such as harm reduction, for engaging clients who may have low intention or motivation to quit. Alternatively, behavioral strategies aimed at increasing motivation to quit, such as motivational interviewing with goal setting, should be incorporated and enhanced. While our study found that quit medication did not differ by mode of entry, quitlines should implement policies that support cessation for high-risk groups who may experience barriers in access to care and difficulty navigating complex health systems. Medicaid beneficiaries greatly underuse cessation medications compared to those with private insurance [17]. Nationally, only $10 \%$ of Medicaid beneficiaries who smoke fill a prescription for a tobacco cessation medication annually [33]. Although policies that limit the distribution of NRT to certain client groups may decrease quitline costs, reliance on external coverage of cessation medications for high-risk Medicaid smokers may add to barriers when quitting and underuse of cessation treatments.

While medication use did not differ across the three groups in adjusted models, it is important to note that just over half of our sample of quitline clients with Medicaid reported medication use (Table 1). This appears to be much lower than the overall medication use rate among all ASHLine clients, which was reported at $73 \%$ in a recent study [18]. Future research should compare medication use among quitline clients with Medicaid and those without Medicaid who receive quitline provided NRT to assess overall differences in medication use and quit rates. This would help further understand the impact of quitlines limiting NRT and having to rely on external insurers for medication coverage, especially among high-risk groups such as Medicaid beneficiaries.

\section{Strengths and limitations}

This study was conducted in a state quitline setting, which included a large sample size and identified the real-world implications of limiting tobacco treatment services to a high-risk population. These translational findings can inform other state quitlines looking to leverage externally provided treatment to residents. Medication use and quit rates were collected at seven month follow-up survey. Although our survey completion rates were low (41.5\%) and represent a potential source of response bias, these response rates are common among state quitlines. While NAQC has established a goal of $50 \%$ follow-up, most state quitlines fall well below this recommendation since loss to follow-up is common [19]. Secondly, we did not assess adherence and usage of NRT. While clients may self-report using NRT at the end of program, we did not assess whether clients used their full supply or if they adhered to usage guidelines at follow-up. While this paper aims to assess access to quit medications and associated quit outcomes among Arizona's Medicaid quitline client population, further research may examine adherence to medication use. Medication use and quit status were self-reported are not verified biochemically. However, self-reported smoking status has been shown to be reliable and is common practice in tobacco research [34]. It is also important to note that our study only assessed for intention to quit in the next 30 days and did not assess for motivation to quit.

\section{Conclusions}

This study highlights differences in Medicaid client characteristics by mode of entry and tobacco cessation medication use and quit rates. Higher intention to quit, social support, education levels, and race and ethnicity may play an important role in quit rates. State quitlines should tailor services to address these factors and social determinants of health within high-risk, low-income smokers such as Medicaid beneficiaries. State quitlines and funding agencies should consider the implications of limiting quitline services in high-risk populations and implement policies that reduce barriers and support smoker engagement.

\section{Additional file}

Additional file 1: Table S1. Descriptive statistics between AHCCCS clients analyzed ( $N=3397)$ and AHCCCS clients dropped due to missing data $(N=7795)$. Mean $(S D)$ shown for continuous variables, frequencies (\%) shown for categorical variables. (DOCX 22 kb) 


\section{Abbreviations}

AHCCCS: Arizona Health Care Cost Containment System; ASHLine: Arizona Smokers' Helpline; NAQC: North American Quitline Consortium; NRT: Nicotine Replacement Therapy

\section{Funding}

This research was supported by Arizona Department of Health Services Grants (ADHS11-007339, ADHS16-106672, and ADHS13-026130:5) and the National Cancer Institute (P30 CA023074). The funding bodies were not involved in the study design, data collection, analysis, and interpretation of this manuscript.

\section{Availability of data and materials}

The datasets generated and/or analyzed during the current study are not publicly available due HIPAA regulations but are available from the corresponding author on reasonable request.

\section{Authors' contributions}

$\mathrm{AL}$ conceptualized the idea, took the lead on writing the paper, generated the hypothesis, interpreted the data, and served as the lead author. RR and UN assisted with data conceptualization and manuscript preparation, PO was the junior biostatistician, MB was senior author and senior biostatistician. All authors read and approved the final manuscript.

\section{Ethics approval and consent to participate}

Since the study used de-identified client data, the study protocol was reviewed and deemed exempt by the University's Institutional Review Board. All participating subjects provided verbal consent obtained over the phone.

\section{Consent for publication}

Not Applicable.

\section{Competing interests}

The authors declare that they have no competing interests.

\section{Publisher's Note}

Springer Nature remains neutral with regard to jurisdictional claims in published maps and institutional affiliations.

\section{Author details \\ ${ }^{1}$ Health Promotion Sciences, University of Arizona, Mel and Enid Zuckerman College of Public Health, 1295 N Martin Ave, Tucson, AZ 85724, USA. ${ }^{2}$ Biostatistics, University of Arizona, Mel and Enid Zuckerman College of Public Health, 1295 N Martin Ave, Tucson, AZ 85724, USA. ${ }^{3}$ Epidemiology and Biostatistics, University of Arizona, Mel and Enid Zuckerman College of Public Health, 1295 N Martin Ave, Tucson, AZ 85724, USA}

\section{Received: 29 March 2018 Accepted: 1 August 2018}

\section{Published online: 10 August 2018}

\section{References}

1. Warren GW, Alberg AJ, Kraft AS, Cummings KM. The 2014 surgeon General's report: 'the health consequences of Smoking-50 years of progress': a paradigm shift in cancer care. Cancer. 2014;120(13):1914-6.

2. M. Vijayaraghavan, S. A. Schroeder, and M. Kushel, "The effectiveness of tobacco control policies on vulnerable populations in the USA: a review," Postgrad. Med. J., 2016

3. Jamieson DJ, Uyeki TM, Callaghan WM, Meaney-Delman D, Rasmussen SA. Center for Disease Control and Prevention, "Best Practices for Comprehensive Tobacco Control Programs - 2014". Obstet Gynecol. 2014; 124(5):1005-10.

4. Xu X, Bishop EE, Kennedy SM, Simpson SA, Pechacek TF. Annual healthcare spending attributable to cigarette smoking: an update. Am J Prev Med. 2015;48(3):326-33.

5. CDC, "National Health Interview Survey: Tables of Summary Health Statistics," 2013. Available:https://ftp.cdc.gov/pub/Health_Statistics/NCHS/ NHIS/SHS/2013_SHS_Table_A-12.pdf. Accessed 6 Aug 2018.

6. Stead LF, et al. Nicotine replacement therapy for smoking cessation. Cochrane Database of Systematic Reviews. 2012;11(11):CD000146.
7. Cummings KM, Fix B, Celestino P, Carlin-Menter S, O'Connor R, Hyland A. Reach, efficacy, and cost-effectiveness of free nicotine medication giveaway programs. J Public Health Manag Pract. 2006;12(1):37-43.

8. Tinkelman D, Wilson SM, Willett J, Sweeney CT. Offering free NRT through a tobacco quitline: impact on utilisation and quit rates. Tob Control. 2007;16: 42-6.

9. Hopkins DP, et al. Reviews of evidence regarding interventions to reduce tobacco use and exposure to environmental tobacco smoke. Am J Prev Med. 2001;20(2S):16-66.

10. Stead LF, Perera R, Lancaster T. Telephone counselling for smoking cessation. Cochrane Database Syst. Rev. 2006;3(8):CD002850.

11. North American Quitline Consortium, "Quitline Profiles for United States." [Online] Available: http://map.naquitline.org/profile/usa/. [Accessed 14 Jun 2017].

12. United States Department of Labor, "Faqs About Affordable Care Act Implementation ( Part Xix )," 2014. [Online]. Available: https://www.dol.gov/ sites/default/files/ebsa/about-ebsa/our-activities/resource-center/faqs/acapart-xix.pdf. [Accessed: 08 Feb 2017].

13. Burns EK, Hood NE, Goforth E, Levinson AH. Randomised trial of two nicotine patch protocols distributed through a state quitline. Tob Control. 2016;25(2):218-23.

14. Cole S, Suter C, Nash C, Pollard J. Impact of a temporary NRT enhancement in a state Quitline and web-based program. Am. J. Health Promot. 2016; 32(5):1206-13.

15. Rhodes KV, et al. Primary care access for new patients on the eve of health care reform. JAMA Intern Med. 2014;174(6):861-9.

16. Huang ES, Finegold K. Seven million Americans live in areas where demand for primary care may exceed supply by more than 10 percent. Health Aff. 2013:32(3):614-21.

17. Cokkinides VE, Ward E, Jemal A, Thun MJ. Under-use of smoking-cessation treatments: results from the National Health Interview Survey, 2000. Am J Prev Med. 2005;28(1):119-22.

18. Nair US, Reikowsky RC, Wertheim BC, Thomson CA, Gordon JS. Quit outcomes and program utilization by mode of entry among clients enrolling in a Quitline. Am J Health Promot. 2018;1:890117117749366.

19. North American Quitline Consortium. Measuring Quit Rates. Quality Improvement Initiative. Phoenix, AZ; 2009. Available: https://cdn.ymaws. com/www.naquitline.org/resource/resmgr/docs/naqc_issuepaper_ measuringqui.pdf. Accessed 6 Aug 2018.

20. Pomerleau CS, Carton SM, Lutzke ML, Flessland KA, et al. Reliability of the Fagerström tolerance questionnaire and the Fagerström test for nicotine dependence. Addict. Behav. 1994;19(1):33-9.

21. Fagerström K. Determinants of tobacco use and renaming the FTND to the Fagerström test for cigarette dependence. Nicotine and Tobacco Research. 2012;14(1):75-8.

22. Pomerleau CS, Majchrzak MJ, Pomerleau OF. Nicotine dependence and the Fagerstrom tolerance questionnaire: a brief review. J Subst Abus. 1989;1(4): 471-7.

23. Heatherton TF, Kozlowski LT, Frecker RC, Fagerstrom KO. The Fagerstr??M test for nicotine dependence: a revision of the Fagerstrom tolerance questionnaire. Br J Addict. 1991;86(9):1119-27.

24. Nair US, Bell ML, Yuan NP, Wertheim BC, Thomson CA. Associations between comorbid health conditions and quit outcomes among smokers enrolled in a state Quitline, Arizona, 2011-2016. Public Health Rep. 2018; 133(2):200-6.

25. Jung AM, Schweers N, Bell ML, Nair U, Yuan NP. Tobacco use cessation among quitline callers who implemented complete home smoking bans during the quitting process. Prev. Chronic Dis. 2017;26(14):E105.

26. Nair US, Brady B, O'Connor P, Bell ML. Factors predicting client re-enrolment into tobacco cessation services in a state quitline. Prev Chronic Dis. In Press. 2018;15:18_0144.

27. United States Department of Health and Human Services. The Health Consequences of Smoking - 50 Years of Progress A Report of the Surgeon General. A Rep. Surg. Gen. 2014:1081.

28. North American Quitline Consortium (NAOC). The Minimal Data Set for Evaluating Quitlines. Phoenix, AZ; 2012.

29. Hosmer DW, Lemeshow S. Goodness of fit tests for the multiple logistic regression model. Commun Stat - Theory Methods. 1980;9(10):1043-69.

30. Desquilbet L, Mariotti F. Dose-response analyses using restricted cubic spline functions in public health research. Stat Med. 2010;29(9):1037-57.

31. Song G, Landau AS, Gorin TJ, Keithly L. Real-world impact of quitline interventions for provider-referred smokers. Am J Prev Med. 2014;47(4):392-402. 
32. Willett JG, et al. Clinical faxed referrals to a tobacco Quitline. Reach, enrollment, and participant characteristics. Am J Prev Med. 2009;36(4):337-40.

33. Ku L, Bruen BK, Steinmetz E, Bysshe T. Medicaid tobacco cessation: big gaps remain in efforts to get smokers to quit. Health Aff. 2016;35(1):62-70.

34. Patrick DL, Cheadle A, Thompson DC, Diehr P, Koepsell T, Kinne S. The validity of self-reported smoking: a review and meta-analysis. Am J Public Health. 1994;84(7):1086-93.

Ready to submit your research? Choose BMC and benefit from:

- fast, convenient online submission

- thorough peer review by experienced researchers in your field

- rapid publication on acceptance

- support for research data, including large and complex data types

- gold Open Access which fosters wider collaboration and increased citations

- maximum visibility for your research: over $100 \mathrm{M}$ website views per year

At $\mathrm{BMC}$, research is always in progress.

Learn more biomedcentral.com/submissions 